\title{
Post-transplant lymphoproliferative disorder of the ileum diagnosed by double-balloon enteroscopy
}

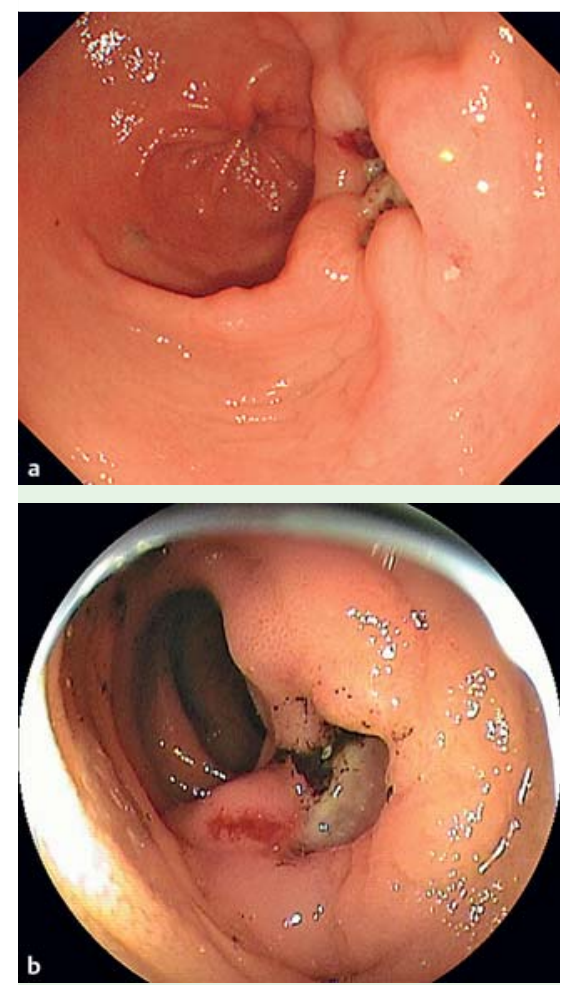

Fig. 1 Endoscopic images showing: a an ulcer seen during esophagogastroduodenoscopy on the posterior wall of the stomach (later histological diagnosis was nonspecific); b multiple ulcers detected in the ileum by double-balloon enteroscopy (DBE).

Post-transplant lymphoproliferative disorder (PTLD) is a common life-threatening complication after solid-organ transplantation that is mostly related to EpsteinBarr virus (EBV) infection [1]. PTLD occurs in $6.2 \%$ of lung transplants, $5.2 \%$ of kidney and pancreas transplants, $2 \%$ of heart transplants, and $1.4 \%$ of liver transplants [2]. Although around $15 \%$ of patients present as an emergency with intestinal perforation [3], there are only a few reports of cases in which PTLD lesions in the small intestine have been observed endoscopically. We report a case of PTLD involving the ileum that occurred 11 months after heart transplantation and was detected during double-balloon enteroscopy (DBE).

A 49-year-old man who had undergone a heart transplant 11 months previously and was receiving $10 \mathrm{mg}$ tacrolimus,
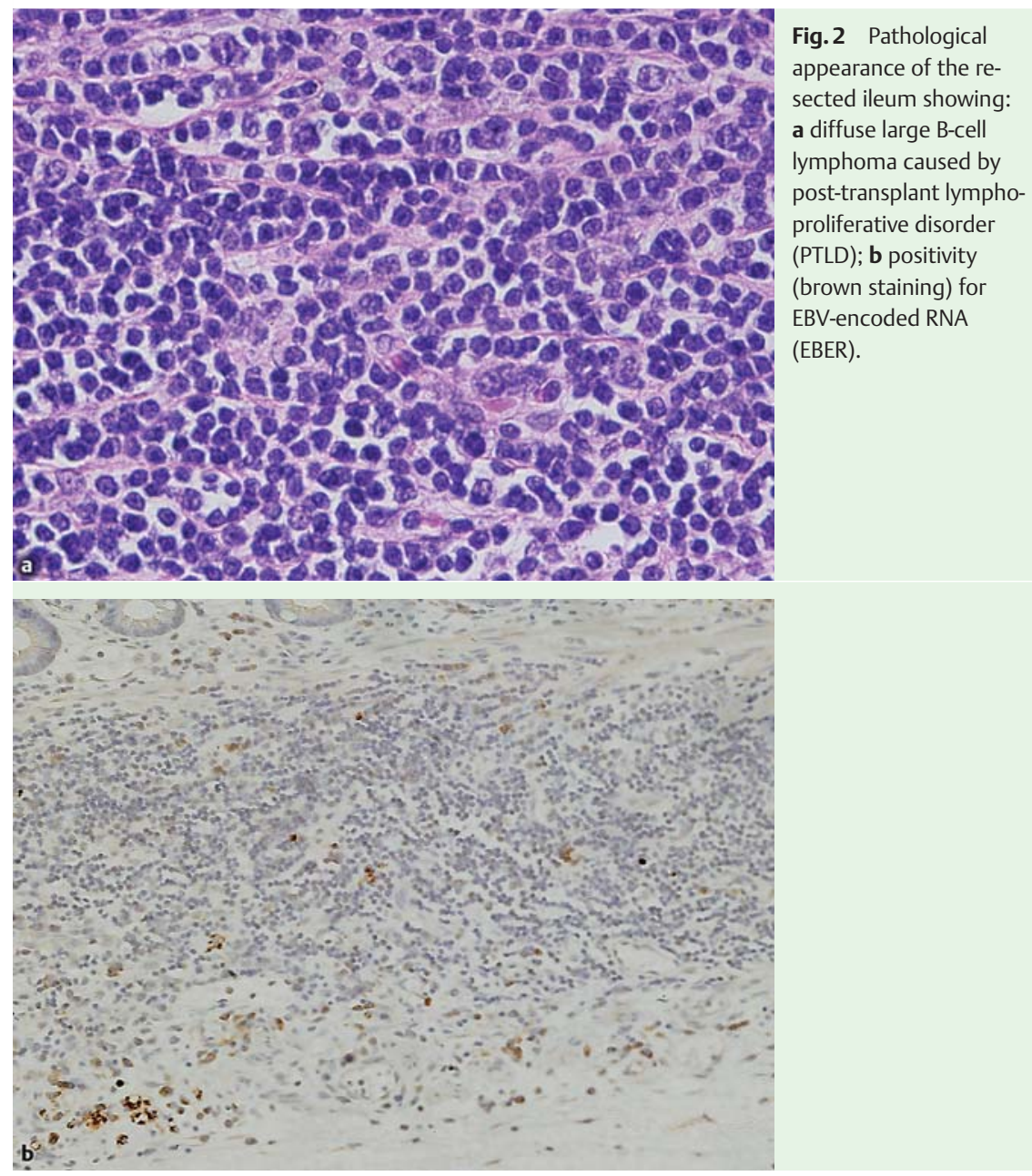

emergent segmental ileal resection. Pathological examination of the resection specimen revealed a diagnosis of diffuse large B-cell lymphoma caused by PTLD ( $\bullet$ Fig.2a) and staining for EBV-encoded RNA (EBER) was positive ( $\bullet$ Fig. 2 b). He therefore received treatment with rituximab, and a subsequent FDG-PET scan showed that the FDG-avid stomach lesion had disappeared.

There have been few reported cases of PTLD-related ileal lesions being diagnosed by endoscopy. Nevertheless, the possibility of PTLD must be considered when multiple ileal ulcers are observed after organ transplantation.

\section{Endoscopy_UCTN_Code_CCL_1AC_2AC}

Competing interests: None 
Seiichi Tawara, Shinichiro Shinzaki, Tsutomu Nishida, Motohiko Kato, Satoshi Hiyama, Takahiro Inoue, Hideki lijima, Masahiko Tsujii, Tetsuo Takehara

Department of Gastroenterology and Hepatology, Graduate School of Medicine, Osaka University, Osaka, Japan

\section{References}

1 Tanner JE, Alfieri C. The Epstein-Barr virus and post-transplant lymphoproliferative disease: interplay of immunosuppression, $\mathrm{EBV}$, and the immune system in disease pathogenesis. Transpl Infect Dis 2001; 3: 60-69

2 Walker RC, Paya CV, Marshall WF et al. Pretransplantation seronegative Epstein-Barr virus status is the primary risk factor for posttransplantation lymphoproliferative disorder in adult heart, lung, and other solid organ transplantations. J Heart Lung Transplant 1995; 14: 214-221

3 Kahan BD, Ponticelli C, Montagnino G, eds. Principles and practice of renal transplantation. London: Martin Dunitz; 2000
Bibliography

DOI http://dx.doi.org/

10.1055/s-0033-1344828

Endoscopy 2013; 45: E380-E381

(C) Georg Thieme Verlag KG

Stuttgart · New York

ISSN 0013-726X

Corresponding author

\section{Seiichi Tawara, MD}

Osaka University - Gastroenterology and Hepatology

2-2, Yamadaoka Suita

Osaka 5650871

Japan

Fax: +81-66-8793629

twr@gh.med.osaka-u.ac.jp 